Article

\title{
Effects of Higher Education Levels on Total Factor Productivity Growth
}

\author{
Jie Liu ${ }^{1}$ (D) and Chao $\mathrm{Bi}^{2, *}$ \\ 1 School of Humanities, Economics and Laws, Northwestern Polytechnical University, Xi'an 710072, China; \\ liujie01@nwpu.edu.cn \\ 2 International Business School, Shaanxi Normal University, Xi'an 710119, China \\ * Correspondence: xabichao@126.com
}

Received: 31 December 2018; Accepted: 19 March 2019; Published: 25 March 2019

check for updates

\begin{abstract}
China is facing challenges to sustainable economic growth. Higher education of Chinese residents can affect total factor productivity (TFP) growth and hence has an influence on economic sustainability. However, currently, there is limited literature on the nexus between higher education and TFP in China. Therefore, this paper empirically analyzes the heterogeneous and spatial effect of higher education on the regional TFP growth using a dynamic spatial econometric model with provincial panel data from 2003 to 2016. The results indicate that different levels of higher education have significant effects on TFP growth and are mainly reflected in the spatial spillover effect. Bachelor and doctoral education (particularly doctoral education) demonstrated significant positive effects, whereas the technical school and master education had significant negative effects. When decomposing this effect into technical efficiency and technical progress to explore the mechanism of influences, the latter plays the major role. Therefore, the Chinese government can promote TFP growth and economic sustainability by expanding the scale of bachelor and doctoral education and improving the quality of technical and master education.
\end{abstract}

Keywords: education heterogeneity; spatial spillover effects; total factor productivity growth; dynamic spatial SLX model

\section{Introduction}

Although China's economy has experienced a long period of double-digit growth since the 1990s, China is facing numerous challenges to sustainable economic growth. One of the prominent characteristics of the high-speed growth in China is that it relies heavily on resources input (e.g., natural resources, human resources, financial resources, environmental resources, etc.), which is not sustainable [1]. Improving total factor productivity (TFP), which is a measurement of the output efficiency of all production factors, can solve the sustainability question for the reason that TFP growth can promote economic growth continuously and steadily without additional resources input $[2,3]$. Higher education, which provides training of critical thinking, technological skills, and literacy, would cultivate educated workers to implement tasks more efficiently and hence improve a country's TFP and sustainable economic growth [4]. However, based on the current literature, there are limited studies that explore the relationship between higher education and TFP growth in China. Therefore, exploring the nexus between higher education and TFP growth deserves more attention. Undoubtedly, it is not only an important area of research, but also a matter of considerable interest to policymakers.

Although much research has examined the relationship between higher education and TFP, in general, the literature has not yet reached a definitive conclusion. From the theoretical perspective, Lucas indicated that average human capital can theoretically improve TFP [5]. Then, Romer extended this model with the idea that increasing the number of innovative talents also aids the economy [6]. 
Empirically, Hua indicated that higher education, rather than primary education, significantly affects TFP [7]. Gu et al. (2017) contended that graduate education can improve the economy through its spillover effects [8]. In agreement, Bloom noted that this effect is particularly prominent in developing countries [9]. Adversely, a few pieces of literature indicate that higher education does not have a significant influence on economic productivity. Using a sample of countries belonging to the Organization for Economic Co-operation and Development, Wolff (2001) revealed that the number of higher education graduates does not significantly affect economic productivity [10]. Vedder (2004) found that states with greater public expenditures on higher education did not obtain more economic growth in the US [11]. Guo and Jia (2009) constructed a two-step human capital accumulation model and observed that compared to primary education, the effect of higher education on economic productivity is ambiguous [12].

There are three reasons to explain why these conclusions above are inconsistent. First, higher education could increase employment and improve the safety of society, and any results that do not consider these points are biased [13]. Second, according to Hanushek (2016), extending the years of education without improving human capital does not influence economic productivity [14]. Lastly, Di and Sun (2014) revealed that different types of higher education have distinct impacts on economic efficiency and growth [15]. Overall, the overwhelming majority of the literature has discussed education in general, but few studies have distinguished among various higher education levels.

This paper explores the effect of higher education on TFP growth using a dynamic spatial econometric method with panel data from 2003 to 2016 in China. The main contributions of the paper are as follows. First, this paper takes the heterogeneity of higher education into consideration and divides higher education into four different levels (e.g., technical education, bachelor education, master education, and doctoral education), which makes it possible to explore the impact of different levels of higher education on TFP growth. Second, this paper takes the inter-provinces mobility of higher education graduates into consideration by using a spatial econometrics approach, which makes it possible to estimate the spillover effect of higher education on TFP growth. This method can help assess the effect of higher education on TFP growth more accurately since the number of higher education graduates of the specific province is inconsistent with the net recipient of new human capital into this province. The paper is structured as follows: Section 2 displays assumptions; Section 3 details the methodology and variables selection; Section 4 summarizes the benchmark estimations and main results; and Section 5 provides conclusions and policy implications.

\section{Assumptions}

\subsection{Heterogeneous Human Capital and Regional TFP Growth}

Becker posited that differences in income can reflect human capital inconsistency [16]. High-level education can promote technical skills and thereby increase TFP growth [17]. In addition, different education levels have distinct targets. For example, the purpose of a technical school is to provide minimum necessary training to begin working in the chosen career field. Bachelor's education aims to provide basic knowledge in a particular area. Master's education trains students with a certain degree of research ability, while doctoral education equips students with skills that encourage innovation based on research ability. Therefore, diverse, target-oriented education influences economic efficiency and growth in different ways. According to Spence's signal theory, graduates with a higher level of education have higher productivity [18]. Many of these graduates probably had a naturally productive mindset before pursuing education, with the diploma attesting to their high human capital potential. The first hypothesis is that discrepant education levels affect regional TFP differently.

\subsection{Graduates' Mobility and TFP Growth}

The development of the economy is unbalanced, and education resources are distributed unevenly; this causes graduates to move across provinces. According to the Chinese Education Statistical 
Yearbook and China Labor Statistical Yearbook, data can be used to calculate the net mobility of higher educated labor. Table 1 displays the accumulated net flow of three levels of the graduates in each province from 2003 to 2016 . We find that there are 15 provinces where technical school students had a net flow in, 17 provinces where bachelor students had a net flow in, and 17 provinces where postgraduate students had a net flow in. The quantities of net flow graduates are 5270 thousand, 4720 thousand, and 800 thousand, respectively. Furthermore, we captured the characteristics of mobility among graduates and the three influential channels: neighboring provinces, state of birth, and developed provinces (In China, developed provinces include Beijing, Tianjin, Shandong, Jiangsu, Shanghai, Zhejiang, Fujian, and Guangdong, which have a relatively high GDP per capita. Most of them are distributed along the eastern coast) [19]. These three patterns of mobility, in fact, represent two reasons for graduates to flow. The first one is that graduates like to work in developed provinces, which means more opportunity and a higher salary. The second is that graduates prefer neighboring provinces and states of birth which they can easily get used to. These data indicate that higher education not only affects the local economy, but also spreads to other provinces [17]. Thus, we present the second assumption that higher education affects the economy through spatial spillover effects.

Table 1. Net Flow of Three Levels of Graduates 2003-2016.

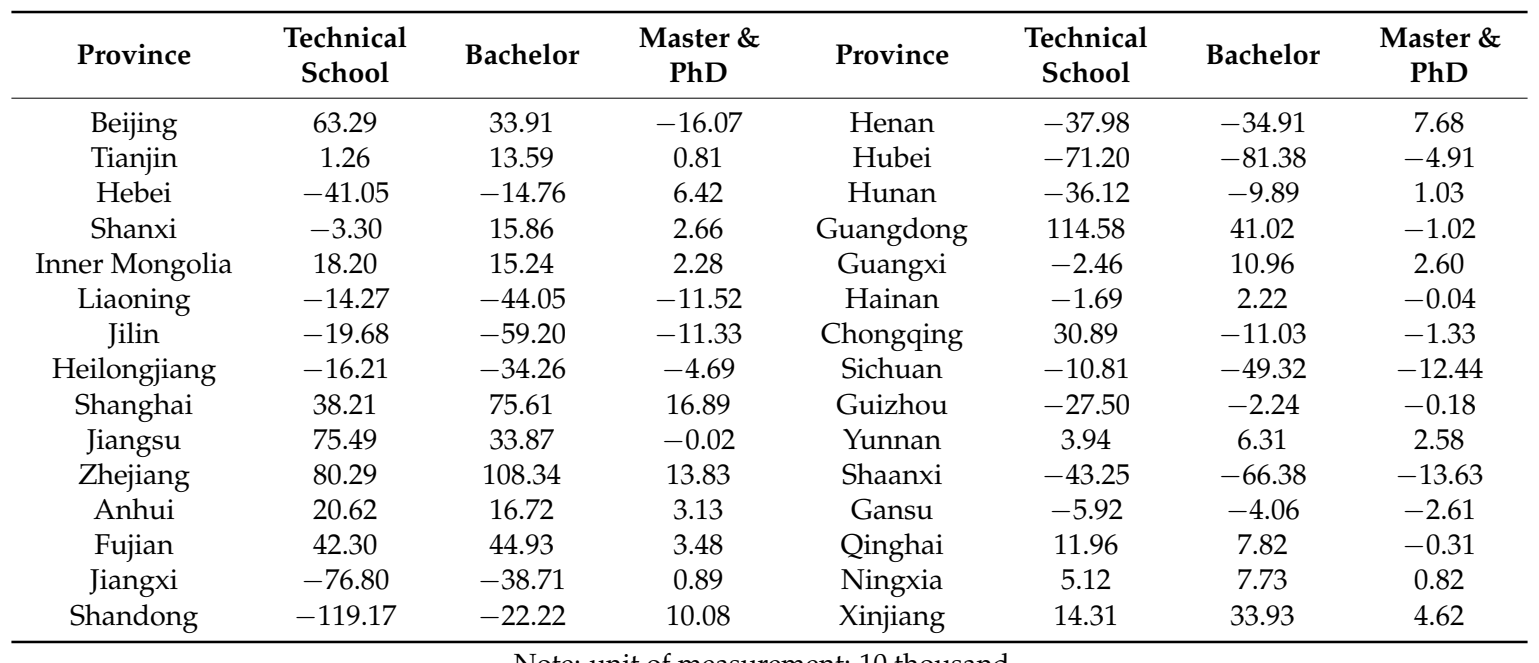

Note: unit of measurement: 10 thousand.

\subsection{Human Capital and TFP Decomposition}

To disentangle the sources of the total factor productivity growth, the decomposition analysis of the TFP index is conducted. In summary, technical progress change and technical efficiency change are two of the most important components driving TFP growth. The technical progress component captures the effects of a shift in the production possibility frontier on productivity (PPF) [20]. The PPF changes its position in response to various shocks arising from technological advances. Human capital embodies knowledge and skills, which play a role in technological advances. On the other hand, the technical efficiency component measures the effects of deviations from the PPF on productivity. This deviation mainly comes from variations in the input utilization efficiency. Higher education could improve the efficiency of input utilization.

Using the Data Envelopment Analysis (DEA) method, the production possibility frontier (PPF) can be obtained. Technical progress is signified by the expansion of PPF; conversely, retreating of PPF represents technical regression [21]. Technical efficiency indicates a movement towards the production possibility frontier. If movement towards PPF is less than the PPF expansion, technical efficiency decreases, or vice versa. The third assumption is that either technical progress change or technical efficiency change could be channels for human capital impacting TFP growth. 


\section{Methodology and Selections of Variables}

\subsection{Empirical Model}

Spatial econometric models often focus on spillover effects, such as whether a change to the level of higher education in a particular province affects the TFP growth in neighboring provinces. Comparisons of point estimates from those derived from non-spatial models, with the findings of spatial econometric models, may lead to erroneous conclusions. The objective of this study is to establish a rationale for the different spatial lags and spatial weight matrices, which best fit the data, and provide a clearer understanding of the impact of neighboring provinces on human capital. To deal with spatial interactions among geographical units, spatial lags that are co-determinants in the dependent variable, the explanatory variables, and the error term from neighboring or other provinces should be used following the spatial econometrics literature [22]. Two crucial issues involved in specifying a spatial econometric model are the choice of the type of spatial lags and the choice of a weight matrix. The objective of this study is to establish a rationale for identifying which types of spatial lags in combination with which type of spatial weight matrix best fit the data. Accordingly, this study considers seven spatial econometric models' specifications and three potential specifications of the spatial weight matrix in an empirical analysis. These combinations are tested within a common framework.

The spatial econometric model is a linear regression model (to estimate the effects of four education levels of human capital on TFP growth, we assumed a linear relationship, which is based on Abbas et al. (2000) [23]. They estimate the standard growth accounting model with human capital as a factor production, that is, Cobb-Douglas production function extension. After taking the log of the model, the linear relationship between education level and economic growth exists.) extended to include spatial lags in the dependent variable, the explanatory variables, or some combination thereof. Including all spatial lags yields a so-called general spatial nesting model. In addition to a static model, Goldsmith (2007) considers a dynamic model that contains the temporal lag of the variables to control for persistence [24]. This extension is known as the dynamic general spatial nesting model [25]:

$$
y_{t}=a y_{t-1}+\rho W_{1} y_{t}+g_{t-1} \beta+W_{2} g_{t-1} \theta+W_{3} g_{t-1} v+V_{t} \gamma+\varepsilon_{t}
$$

where $y_{t}$ denotes an $N \times 1$ vector of the TFP growth for every province in the sample during time period $t ; g_{t-1}$ is an $N \times 4$ matrix of exogenous explanatory variables, which denote one period lag for four higher education levels of graduates; $V_{t}$ represents the control variable, in the $N \times K$ matrix, where $k$ denotes the number of control variables; $\alpha, \rho, \beta, \theta, \gamma$, and $v$ measure the strength of these spatial lags; and finally, $\varepsilon_{t}$ is the stochastic error term.

Basically, there are three main types of spatial lags that can be used to explain provincial TFP growth [26]. First, an endogenous spatial lag measures whether the TFP growth of province $i$ depends on the TFP growth of other province $j$, or vice versa, resulting in the spatial autoregressive (SAR) model. $W_{1} y_{t}$ in the right hand can represent it and this $y_{t}$ denotes TFP growth in other provinces $j . W_{1}$ is the spatial weight matrix in endogenous spatial lag. Second, exogenous spatial lags can measure whether the TFP growth of country $i$ depends on the explanatory variables of other provinces $j$. Models containing these lags are the spatial lag of $\mathrm{X}$ models (SLX). $W_{2} g_{t-1}$ in the right hand represents exogenous spatial lags. $W_{2}$ is the spatial weight matrix in exogenous spatial lag. Third, a spatial lag among the error term might be pertinent if countries share similar unobserved characteristics or face similar unobserved institutional environments. Models that rely on this lag are known as spatial error models (SEM).

The spatial weight matrix can model mutual relationships among provinces, which is another crucial issue for determining which set of provinces might affect the local province. Generally, spatial weight matrix elements can depend on geographical and economic distances between provinces. $W$ is an $N \times N$ non-negative spatial weight matrix, whose diagonal elements are 0 because a province 
cannot be its own relatives [22]. For this study, we use two principles to construct three spatial weights. (1) A province may respond to other provinces of even more distant provinces because of economic factors. Graduates in developing provinces are more likely to flow to developed provinces. Therefore, we construct a matrix in which these provinces' economic activities interact, and then combine it using economic distance, $W_{1}$ and $W_{2}, w_{i, j}=P G D P_{j} / P G D P_{i}$ [27]. It denotes the effect of GDP per capita in province $j$ on GDP per capita in province $i$ to reflect the spillover effect. (2) Sharing a common land or maritime border [24,28] implies the binary $(0 / 1)$ contiguity matrix, $W_{3}$.

Another one of the biggest problems in empirical spatial econometric research is choosing among different model specifications. Too many studies only consider one type of spatial lag, resulting in just an SAR, SEM, or SLX model, whereas we test the model specifications against one another later.

\subsection{Variable Selection}

\subsubsection{Dependent Variables}

TFP growth (tfpch) is the dependent variable. Comparing the advantages and disadvantages of TFP calculation methods, we selected the DEA-Malmquist productivity index to estimate TFP growth [29]. Data drawn from the provincial statistical yearbook included GDP, labor, and capital per province [30].

\subsubsection{Independent Variables}

Independent variables were the number of graduates for the four education levels, namely technical schools, bachelor's, master's, and doctoral education.

\subsubsection{Control Variables}

Based on a literature review of factors influencing TFP growth [31], we used capital per capita (capital) by using the capital-labor ratio, which can improve technical progress and openness (trade) by using the total import-export of GDP ratio. More openness indicates that the province has a higher possibility of improving its efficiency. We calculated the total demand fluctuation (demand) by using total retail sales of consumer goods in the whole society of GDP ratio; in general, an increase in demand encourages an enterprise to increase investment in production, rather than $R \& D$. We also calculated the labor input scale (inscale) to control the influence of factor input scale change on TFP growth.

A summary of the variables is presented in Table 2. Considering enlarged enrollment policy, we selected a sample span of the years 2003-2016. Based on the standard error and average value, it is easy to find that TFP growth, its decomposition, and graduates obviously differ among provinces. According to the average TFP growth of each province, Beijing (0.302), Tianjin (2.845), Shanghai (3.478), Jiangsu (2.195), Zhejiang (0.311), and Guangdong (-0.601), which are all distributed in eastern of; whereas Anhui (-2.764), Henan (-5.667), Guangxi (-6.227), Xizang (-6.858), which belong to Middle and Western part. It is obvious that TFP growth differs among provinces and eastern provincial TFP growth is larger than in the middle and western provinces. As for higher educated graduates, taking undergraduates, for instance, there are 10 provinces exceeding 100 thousand, which are Beijing $(102,075)$, Hebei $(107,860)$, Jiangsu $(181,985)$, Shandong $(166,083)$, Henan $(134,396)$, Hubei $(148,525)$, Hunan $(106,582)$, Guangdong $(137,745)$, Shaanxi $(112,089)$, and Sichuan $(124,420)$; on the contrary, Xizang, Qinghai, and Ningxia only have 3487, 5424, and 9369 undergraduates, respectively. 
Table 2. Summary of variables.

\begin{tabular}{ccccc}
\hline Variables & Average & Standard Error & Min & Max \\
\hline tfpgrowth & -2.622 & 3.616 & -15.808 & 9.650 \\
technical progress & -1.450 & 4.403 & -18.430 & 11.563 \\
technical efficiency & -1.084 & 3.900 & -9.783 & 21.431 \\
technical school & 84.193 & 68.071 & 1.144 & 293.593 \\
undergraduate & 79.250 & 57.645 & 0.491 & 245.900 \\
master & 10.585 & 11.024 & 0.014 & 71.661 \\
doctor & 1.398 & 2.342 & 0.000 & 16.968 \\
capital per capita & 1.326 & 0.898 & -4.009 & 4.880 \\
trade & -0.005 & 0.078 & -0.414 & 0.312 \\
demand & 0.006 & 0.017 & -0.031 & 0.157 \\
labor input scale & 0.359 & 0.502 & -2.417 & 3.411 \\
\hline
\end{tabular}

\section{Empirical Results}

\subsection{The Spillover Effect of Heterogeneous Human Capital on Regional TFP Growth}

To compare each nest relationship, we can simultaneously identify the most likely spatial econometric model and the most likely spatial weight matrix. To ensure the rationality of empirical models, we estimated models (1)-(7) and used the Likelihood Ratio (LR) test, the Akaike Information Criterion (AIC), and Bayesian Information Criterion (BIC) rules. We also display static and dynamic versions of the model specifications; the latter includes the TFP growth indicator lagged in time. Table 3 contains the different models in combination with three proposed spatial weight matrices. The first column represents the results of the dynamic panel model (DPM). The second and third columns signify the dynamic spatial lagged independent variables. Columns 4, 5, 6, and 7 represent the dynamic spatial autoregression (DSAR) model, dynamic spatial errors model (DSEM), dynamic spatial Durbin model (DSDM), and dynamic spatial Durbin errors model (DSDEM), respectively. The dependent variable is regional TFP growth. After applying the LR test and the Hausman test, we chose the fixed effect model and used the quasi-maximum-likelihood method to make the estimation.

Table 3 reports the estimation results, where LR1 is the likelihood ratio of dynamic models to static models. The results show that regardless of the matter panel model or the spatial econometric model, we should choose the dynamic form. The last two columns of LR2 significantly rejected the hypothesis that exogenous interaction item $W_{2} g_{t-1}$ is zero. It means that model DSDM is better than DSAR and model DSDEM is better than DSEM. In other words, regional TFP growth had a spatial lag because of independent variables. Although model DSLX also contains an exogenous interaction item, it does not include endogenous spatial interaction items $W_{1} y_{t}$ and $W_{1} u_{t}$. According to the LR3, insignificant results indicate that compared to DSDM and DSDEM, DSLX is better off. Furthermore, the difference between Model DSLX1 and DSLX2 is that the latter contains spatial weight matrix $W_{3}$. $W_{3}$ is an adjacency matrix, representing spillover effects from neighboring provinces. Whether to include this part in the model depends on the third column of LR2. Results significantly reject the hypothesis that adjacency matrices / are zero. Therefore, DSLX2 is identified as the most likely spatial econometric model. AIC and BIC rules verify this as well and we finally chose the model DSLX2.

According to the estimation results from model DSLX2, we found that the coefficient of the one-period lag TFP growth is highly significant (1\% level). In addition, the coefficients of the control variables are all consistent with expectations. Specifically, the effect of capital density was not significant, but a negative sign reflected that the return of capital is decreasing, as is TFP growth. The coefficient of openness was significantly positive. Demand fluctuation and input factor scale were significantly negative. These results are consistent with the literature [32]. 
Table 3. Estimation results from basic models.

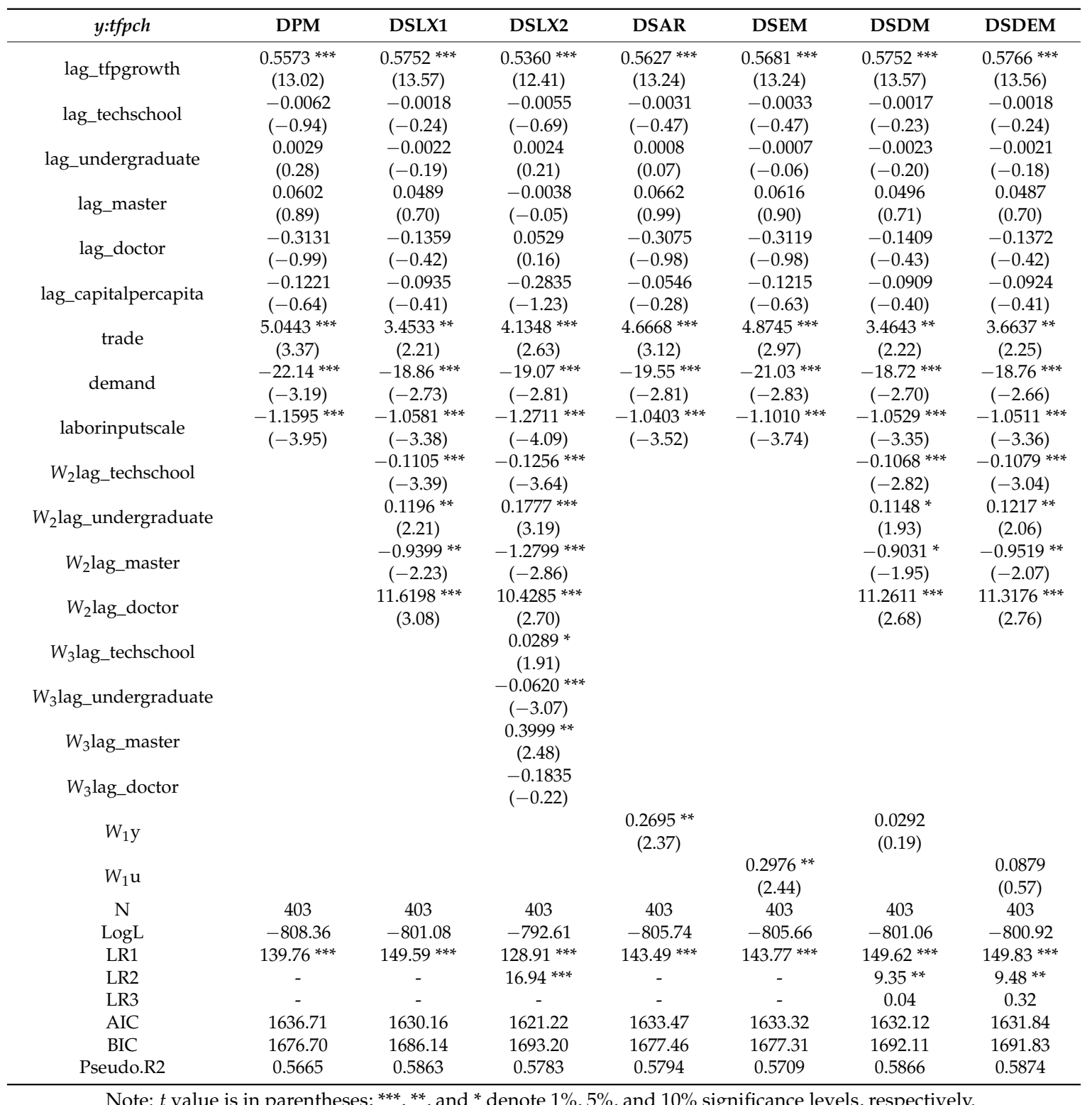

Because of the spatial interaction, the coefficients of the independent variables do not have specific economic meanings. Therefore, we measured the direct and indirect effects of different human capital on TFP growth and used the Markov Chain Monte Carlo (MCMC) method to test the significance level [33]. In Table 4, we compared the short-term effect to long term effect, and it is obvious that the long-term effect was twice that of the short-term effect. This result is consistent with coefficients of the lagged TFP growth, which are significant in Table 3, indicating that graduates have an enlarging effect on TFP growth.

Table 4 indicates that the spillover effects of graduates in all four levels on regional TFP were all significant at the 5\% significance level, whereas the direct effects were all insignificant. This can be viewed as evidence for the first hypothesis, which says that higher education affects the economy through spatial spillover effects. Collins (2013) studied mobility patterns of East Asian students; that is, mobility within Mainland Europe and international mobility of UK students. Collins found that more skilled graduates are more likely to migrate, thereby significantly improving the TFP of destination provinces [34]. Specifically, the influences of different education levels of graduates on regional TFP growth are quite different. Furthermore, the effects of bachelor's and doctoral students are significantly 
positive. TFP increases by $0.0082 \%$ when the number of bachelor's increases by 1000 . TFP growth increases by $0.7159 \%$ when the number of doctoral graduates increases by 1000 . However, as the number of technical school and master's graduates increases, TFP growth decreases. TFP decreases by $0.0071 \%$ as the number of technical school graduates increases by 1000 . Finally, TFP growth decreases by $0.0641 \%$ when the number of master's graduates increases by 1000 . For a robust test, we used education years rather than the number of graduates as independent variables and found that the results were robust (Table 5). Thus, the second hypothesis was supported, showing that discrepant education levels affect TFP differently.

Table 4. Effect of graduates on regional TFP growth.

\begin{tabular}{ccccccc}
\hline \multirow{2}{*}{ y:tfpch } & \multicolumn{3}{c}{ Short Term Effect } & \multicolumn{3}{c}{ Long Term Effect } \\
\cline { 2 - 7 } & Direct Effect & Spillover Effect & Total Effect & Direct Effect & Spillover Effect & Total Effect \\
\hline \multirow{2}{*}{ techschool } & -0.0055 & $-0.0032^{* * *}$ & $-0.0033^{* * *}$ & -0.0119 & $-0.0069^{* * *}$ & $-0.0071^{* * *}$ \\
& $(-0.69)$ & $(-3.01)$ & $(-3.17)$ & $(-0.71)$ & $(-3.02)$ & $(-3.18)$ \\
\hline \multirow{2}{*}{ undergraduate } & 0.0024 & $0.0039^{* *}$ & $0.0038^{* *}$ & 0.0052 & $0.0083^{* *}$ & $0.0082^{* *}$ \\
& $(0.21)$ & $(2.18)$ & $(2.22)$ & $(0.20)$ & $(2.17)$ & $(2.23)$ \\
\hline \multirow{2}{*}{ master } & -0.0038 & $-0.0293^{* *}$ & $-0.0285^{* *}$ & -0.0082 & $-0.0632^{* *}$ & $-0.0614^{* *}$ \\
& $(-0.05)$ & $(-2.13)$ & $(-2.11)$ & $(-0.05)$ & $(-2.15)$ & $(-2.09)$ \\
\hline \multirow{2}{*}{ doctor } & 0.0529 & $0.3415^{* * *}$ & $0.3322 * * *$ & 0.1141 & $0.7360^{* * *}$ & $0.7159^{* * *}$ \\
& $(0.16)$ & $(2.76)$ & $(2.75)$ & $(0.17)$ & $(2.74)$ & $(2.75)$ \\
\hline
\end{tabular}

Table 5. Long-term effects of education years on regional TFP growth.

\begin{tabular}{cccccccc}
\hline \multirow{2}{*}{$\mathbf{y}$} & $\mathbf{X}$ & \multicolumn{2}{c}{ Direct Effect } & \multicolumn{2}{c}{ Spillover Effect } & \multicolumn{2}{c}{ Total Effect } \\
\cline { 3 - 8 } & & Coefficient & $\boldsymbol{t}$ Value & Coefficient & $\boldsymbol{t}$ Value & Coefficient & $\boldsymbol{t}$ Value \\
\hline \multirow{3}{*}{ tfpgrowth } & techschoolh & -0.0008 & -0.69 & $-0.0005^{* * *}$ & -3.01 & $-0.0005^{* * *}$ & -3.17 \\
& undergraduatea & 0.0003 & 0.21 & $0.0005^{* *}$ & 2.18 & $0.0005^{* *}$ & 2.22 \\
& master & -0.0004 & -0.05 & $-0.0033^{* *}$ & -2.13 & $-0.0032^{* *}$ & -2.11 \\
& doctor & 0.0050 & 0.16 & $0.0320^{* * *}$ & 2.76 & $0.0311^{* * *}$ & 2.75 \\
\hline
\end{tabular}

\subsection{Channels of Heterogeneous Human Capital affect Regional TFP Growth: Decomposition}

To explore the pathway of different education levels on TFP growth, we decomposed TFP growth into the technical progress factor and technical efficiency factor, utilizing the DSLX model for testing. The results are shown in Table 6.

Table 6. Long-term effects of human capital on regional TFP growth decomposition.

\begin{tabular}{cccccccc}
\hline \multirow{2}{*}{$\mathbf{y}$} & $\mathbf{X}$ & \multicolumn{2}{c}{ Direct Effect } & \multicolumn{2}{c}{ Spillover Effect } & \multicolumn{2}{c}{ Total Effect } \\
\cline { 3 - 8 } & & Coefficient & $\boldsymbol{t}$ Value & Coefficient & $\boldsymbol{t}$ Value & Coefficient & $t$ Value \\
\hline \multirow{3}{*}{ Technical } & techsch & -0.0023 & -0.23 & $-0.0088^{* * *}$ & -6.72 & $-0.0086^{* * *}$ & -6.74 \\
progress & undergraduatea & -0.0047 & -0.33 & $0.0040^{*}$ & 1.83 & $0.0037^{*}$ & 1.75 \\
& master & 0.0218 & 0.24 & $-0.0300^{*}$ & -1.76 & $-0.0283^{*}$ & -1.7 \\
& doctor & 0.4462 & 1.1 & $0.7316^{* * *}$ & 4.76 & $0.7224^{* * *}$ & 4.81 \\
\hline \multirow{3}{*}{ Technical } & techschoolh & -0.0056 & -0.31 & $0.0077^{* *}$ & 3.26 & $0.0073^{* *}$ & 3.17 \\
efficiency & undergraduatea & 0.0111 & 0.43 & 0.0027 & 0.69 & 0.0030 & 0.78 \\
& master & -0.0983 & -0.61 & -0.0178 & -0.58 & -0.0204 & -0.68 \\
& doctor & -0.1878 & -0.25 & $-0.5596^{* *}$ & -2.04 & $-0.5476^{* *}$ & -2.04 \\
\hline
\end{tabular}

Note: ${ }^{* * *}, * *$, and ${ }^{*}$ denote $1 \%, 5 \%$, and $10 \%$ significance levels, respectively.

It is apparent that technical school graduates would impact TFP growth through both the technical progress channel and technical efficiency channel. However, the technical progress level decreases by $0.0086 \%$, and technical efficiency increases by $0.0073 \%$, with an increase of 1000 graduates. These 
results probably arise since, with the increase of technical school graduates, return to scales decreases and the PPF retreats, so that the technical level regresses. Technical efficiency is improved. Nonetheless, the movement towards the PPF scale is less than the retreated scale, and as a result, the total effect is negative. Bachelor's and master's graduates impact TFP growth only through the technical progress channel; that is, technical progress increases by $0.0037 \%$ with an increase of 1000 bachelor graduates and decreases by $0.0283 \%$ when master graduates increase by 1000 . The negative effects of the master could be as a result of misallocation and over education. For doctoral education, both technical progress and technical efficiency channels were significant, but signs of coefficients are opposite to those found for the technical school education. It is possible that an increase in doctoral graduates can improve PPF, but technical efficiency is not used sufficiently. Overall, the effects are positive.

\subsection{Robust Test}

When defining the spatial weight matrix to represent the spillover effect using economic distance, it could be time-varying, and more importantly, endogenous, in a spatial panel data model. Usual the estimation procedure leads to estimation bias. Qu and Lee (2015) [35] overcome the endogeneity problem by using the law of large numbers (LLN) for the spatial near-epoch dependence (NED) process in a cross-sectional case. Based on this, $\mathrm{Xi}$ et al. (2017) established an asymptotic distribution of quasi-maximum likelihood (QML) estimators by using spatial-time LLN and central limit theorem (CLT) for a martingale difference sequence, which can be applied to the endogenous spatial dynamic situation [36]. In addition, to ensure that the results were robust, we changed the index for TFP growth and run regression again, which is regional GDP per capita instead of TFP growth [37]. Quasi-maximum-likelihood estimation results are displayed in Table 7.

Table 7. Long-term effects of heterogeneous human capital on regional GDP per capita.

\begin{tabular}{ccccccc}
\hline \multirow{2}{*}{ ffpch:GDP/L } & \multicolumn{2}{c}{ Direct Effect } & \multicolumn{2}{c}{ Spillover Effect } & \multicolumn{2}{c}{ Total Effect } \\
\cline { 2 - 7 } & Coefficient & $\boldsymbol{t}$ Value & Coefficient & $\boldsymbol{t}$ Value & Coefficient & $\boldsymbol{t}$ Value \\
\hline Techschool & 0.0011 & 0.16 & $-0.0042^{* * *}$ & -4.14 & $-0.0040^{* * *}$ & -4.07 \\
undergraduate & $-0.0195^{* * *}$ & -1.84 & $0.0028^{*}$ & 1.67 & 0.0020 & 1.27 \\
master & -0.0151 & -0.23 & $-0.0723^{* * *}$ & -5.56 & $-0.0704^{* * *}$ & -5.56 \\
doctor & $0.5606^{* * *}$ & 1.87 & $0.8537^{* * *}$ & 7.43 & $0.8443^{* * *}$ & 7.52 \\
\hline
\end{tabular}

Note: ${ }^{* * *}, * *$, and ${ }^{*}$ denote $1 \%, 5 \%$, and $10 \%$ significance levels, respectively.

Compared to Table 4, we found that the spillover effects remained significant in Table 7. Other than bachelor's education, the three levels of education were all significant at the $1 \%$ level. Based on these robust tests, we conclude that our estimation results are robust.

\section{Conclusions}

Considering the heterogeneous and spatial spillover effects, we constructed a spatial weight matrix to model mutual relationships among provinces according to graduate flowing patterns, and to illustrate the influence of heterogeneous human capital on regional TFP growth from 2003 to 2016. Our conclusions are as follows:

Heterogeneous human capital in different education levels has significant effects on regional TFP growth, and the spatial spillover effect plays an important role. However, different human capital has distinct effects. Bachelor's and doctoral graduates have significantly positive effects on regional TFP growth; nevertheless, the effects of technical school and master's graduates are significantly negative.

Furthermore, we decomposed regional TFP growth into the technical progress factor and technical efficiency factor to explore the influence mechanism. It was concluded that heterogeneous human capital has different channels. Technical school education affects TFP growth through both channels, but has a positive effect on technical efficiency and negative effect on technical progress. Since the technical progress effect is larger than the technical efficiency effect, the total effect is negative; doctoral 
graduates also have two channels to impact TFP growth, but, conversely, the technical progress channel is positive and the technical efficiency channel is negative. The latter is less, and consequently, the total effect is positive. Both undergraduate and master's graduates have only one channel, which is technical progress. The difference is that undergraduates' effect is positive, whereas that for master's is negative.

Given its primary role as a knowledge producer, higher education can serve as a powerful means to help create a more sustainable future. Thus, the concept of 'education for sustainable development' has become, in recent years, one of the core educational initiatives to help address many problems associated with human development. The current study pays attention to the direct impact of higher education itself on economic sustainability, which is one of the important aspects of sustainable development in China. To this extent, the paper suggests another way of thinking about the role of higher education in sustainable development.

The empirical results indicate that higher education has a significant influence on TFP growth and hence affects sustainable economic growth. Furthermore, different levels of higher education have different influences on sustainable economic growth. Therefore, the Chinese government could promote sustainable economic growth by directly adjusting the structure of higher education levels. Specifically, policymakers should optimize the higher education structure by enlarging scales of bachelor and doctoral enrollment in order to make them play a function of improving TFP growth. Based on the empirical results that the effects of master and technical school's graduates on TFP growth are both negative, policymakers should improve the provision quality of such degrees. In addition, the findings suggest that policymakers should encourage higher educated graduates' mobility, particularly bachelor's and doctoral graduates, because they have a significantly positive spillover effect on TFP growth by easing the hukou system in China, which is related to the central government's restrictions on the movement.

Author Contributions: Conceptualization, J.L. and C.B.; methodology, C.B.; software, J.L.; validation, J.L.; formal analysis, J.L.; investigation, J.L.; resources, J.L.; data curation, J.L.; writing-original draft preparation, J.L.; writing-review and editing, J.L.; visualization C.B.; supervision, C.B.; project administration, J.L.; funding acquisition, J.L.

Funding: The research in this paper is jointly funded by the National Social Science Foundation of China (CFA150151), the Fundamental Research Funds for Shannxi Normal University (16SZYB34), and the Fundamental Fund for Central Universities (3102017OQD107).

Acknowledgments: I would like to express my gratitude to all those who have helped me during the writing of this paper. I gratefully acknowledge the help of my supervisor Wei Wei. I do appreciate his professional instructions. Also, I thank Nain for proof reading in the revision process.

Conflicts of Interest: The authors declare no conflict of interest.

\section{References}

1. Feng, C.; Wang, M.; Liu, G.; Huang, J. Sources of economic growth in China from 2000-2013 and its further sustainable growth path: A three-hierarchy meta-frontier data envelopment analysis. Econ. Model. 2017, 64, 334-348. [CrossRef]

2. Dasgupta, P. The idea of sustainable development. Sustain. Sci. 2007, 2, 5-11. [CrossRef]

3. Kumar, S. Is India on a Sustainable Development Path; Yokohama National University: Yokohama, Japan; TERI University: New Delhi, India, 2009.

4. Ahmed, A.; Stein, J.A. Science, technology and sustainable development: A world review. World Rev. Sci. Technol. Sustain. 2004, 1, 5-24. [CrossRef]

5. Lucas, R.E. On the mechanics of economic development. J. Monet. Econ. 1988, 22, 3-42. [CrossRef]

6. Romer, P.M. Endogenous technological change. J. Political Econ. 1990, 98, 71-102. [CrossRef]

7. Hua, P. Impacts of different levels of education on TFP growth: Evidence from China. China Econ. Q. 2005, 4, 147-166. 
8. Gu, J.; Levin, J.S.; Luo, Y. Reproducing academic successors or cultivating versatile experts: Influences of doctoral training on career expectations of Chinese PhD students. High. Educ. 2018, 76, 427-447. [CrossRef]

9. Bloom, D.; Canning, D.; Chan, K.; Luca, D. Higher education and economic growth in Africa. Int. J. Afr. High. Educ. 2014, 1, 22-57. [CrossRef]

10. Wolff, E.N. The Role of Education in the Postwar Productivity Convergence among OECD Countries. Ind. Corp. Chang. 2001, 10, 735-759.

11. Vedder, R. Going Broke by Degree: Why College Costs Too Much; Aei Press: Washington, WA, USA, 2004; Volume 6, p. 294.

12. Guo, Q.; Jia, J. Public education policy, economic growth and human capital premium. Econ. Res. 2009, 10, 22-35.

13. Birdsall, N. Public spending on higher education in developing countries: Too much or too little. Econ. Educ. Rev. 1996, 15, 407-419. [CrossRef]

14. Hanushek, E.A. Will higher education improve economic growth? Oxf. Rev. Econ. Policy 2016, 32, 538-552. [CrossRef]

15. Sun, B.; Ning, X.; University, Q. The value and significance of education modernization for the construction of livable and happy city-The case study of Qingdao. Rev. High. Educ. 2016, 12, 16-23.

16. Becker, G.S. Human Capital: A Theoretical and Empirical Analysis, with Special Reference to Education; National Bureau of Economic Research: New York, NY, USA, 1964.

17. Griliches, Z. Issues in assessing the contribution of research and development to productivity growth. Bell J. Econ. 1979, 10, 92-116. [CrossRef]

18. Spence, M. Job market signaling. Q. J. Econ. 1973, 87, 355-374. [CrossRef]

19. Zhang, K.; Chen, Z.; Economics, S.O. A study of the factors influencing university graduates' employment quality. Popul. Econ. 2017, 1, 75-84.

20. Renuka, M.; Kali, K. Singapore's manufacturing sector's TFP growth: A decomposition analysis. J. Comp. Econ. 2000, 28, 828-839.

21. Hanushek, E.; Kimko, D. Schooling, labor-force quality, and the growth of nations. Am. Econ. Rev. 2000, 90, 1184-1208. [CrossRef]

22. Yesilyurt, M.E.; Elhorst, J.P. Impacts of neighboring countries on military expenditures. J. Peace Res. 2017, 10, 777-790. [CrossRef]

23. Abbas, Q.; Mujahid-Mukhtar, E. The role of human capital in economic growth: A comparative study of Pakistan and India. Pak. Dev. Rev. 2000, 39, 451-473. [CrossRef]

24. Goldsmith, B.E. Arms racing in 'Space': Spatial modelling of military spending around the world. Aust. J. Political Sci. 2007, 42, 419-440. [CrossRef]

25. Silva, D.F.C.D.; Elhorst, J.P.; Neto, R.D.M.S. Urban and rural population growth in a spatial panel of municipalities. Reg. Stud. 2017, 51, 894-908.

26. Ugarte, M.D. Introduction to spatial econometrics. J. R. Stat. Soc. 2011, 174, 513-514. [CrossRef]

27. Ligon, C.E. Economic distance and cross-country spillovers. J. Econ. Growth 2002, 7, 157-187. [CrossRef]

28. Skogstad, K. Defence budgets in the post-cold war era: A spatial econometrics approach. Def. Peace Econ. 2016, 27, 323-352. [CrossRef]

29. Willis, S.L.; Margrett, J.A. Aging and education. Int. Encycl. Soc. Behav. Sci. 2001, 26, $299-304$.

30. Zhang, J.; Wu, G.; Zhang, J. The estimation of China's provincial capital stock: 1952-2000. Econ. Res. J. 2004, $10,35-44$.

31. Isaksson, A. Determinants of Total Factor Productivity: A Literature Review. Research and Statistics Staff Working Paper; United Nations Industrial Development Organization: Vienna, Austria, 2007.

32. Cai, F.; Wang, M. How fast and how far can China's GDP grow? China World Econ. 2002, 5, 9-15.

33. Elhorst, J.P. Spatial Econometrics: From Cross-Sectional Data to Spatial Panels; Springer: Berlin, Germany, 2014.

34. Collins, F.L. Student mobilities, migration and the internationalization of higher education. High. Educ. Policy 2013, 26, 285-288. [CrossRef]

35. Qu, X.; Lee, L.F. Estimating a spatial autoregressive model with an endogenous spatial weight matrix. J. Econom. 2015, 184, 209-232. [CrossRef] 
36. Qu, X.; Lee, L.F.; Yu, J. QML estimation of spatial dynamic panel data models with endogenous time varying spatial weights matrices. J. Econom. 2017, 197, 173-201. [CrossRef]

37. Chen, S.; Chen, D. Haze pollution, government control and economic development. Econ. Res. 2018, 2, $20-34$.

(C) 2019 by the authors. Licensee MDPI, Basel, Switzerland. This article is an open access article distributed under the terms and conditions of the Creative Commons Attribution (CC BY) license (http://creativecommons.org/licenses/by/4.0/). 